\title{
A Unique Case of Concomitant Intraspinal Epidermoid Cyst and Lipoma Associated with Tethered Cord Syndrome
}

\author{
Shrey Jain ${ }^{1, \odot ~ M e d h a ~ A . ~ V y a s ~}{ }^{1} \quad$ Ajit K. Sinha ${ }^{1}$ \\ ${ }^{1}$ Department of Neurosurgery, Sir Ganga Ram Hospital, Delhi, India \\ Address for correspondence Medha A. Vyas, DNB, Room 1242A, \\ Department of Neurosurgery, Sir Ganga Ram Hospital, Old Rajinder \\ Nagar, Delhi 110060, India (e-mail: medhavyas4@gmail.com).
}
Abstract
Keywords
- epidermoid
- tethered Cord
- lipoma
- spinal tumor
- cutaneous stigmata
- congenital spinal
lesion

Patients presenting with pain in lower back and paresthesia in lower limbs may have tethered cord causing the symptomology. Tethered cord may be associated with intradural tumors causing symptoms due to progressive increase in size. Association of tethered cord with single intradural tumor is a common occurrence but, to date, only one case has been reported of tethered cord associated with intradural lipoma and epidermoid cyst. The authors would like to present a similar case in a middle-aged patient.

\section{Introduction}

Tethered cord syndrome is defined as progressively increasing neurological deficits due to limitation of spinal cord movements and traction caused by anatomical or physiological reasons. ${ }^{1}$ It may be associated with different pathologies. Spinal intradural lipoma is rare and slow growing tumor comprising less than $1 \%$ of all intraspinal tumors. ${ }^{2}$ Epidermoid tumors are rare benign lesions, which are common in the intracranial region and account for less than $1 \%$ of all intraspinal tumors. ${ }^{3}$

In this paper, we are presenting a case of a 50-year-old female who was suffering from tethered cord with intradural epidermoid cyst, lipoma and syringomyelia. There has been only one such case report before, and we look forward to contribute. ${ }^{4}$

\section{Case Report}

A 50-year-old female, presented with complaints of insidious onset, gradually progressing, dull aching and persistent low-backache for 8 years. Around 6 months back, she developed nonprogressive tingling sensations in her left lower limb.

DOI https://doi.org/ 10.1055/s-0040-1719235 ISSN 2277-954X.
One week back, she suffered a fall, following which, her complaints aggravated acutely, and she developed tingling sensation in both her lower limbs. She also developed stiffness in both her lower limbs, resulting in experiencing difficulty in walking. There was no history of recent trauma or any aggressive exercise. On neurological examination, there was a dermal pit and a tuft of hair present in the lumbosacral region. There was no wasting in lower limbs. She had spastic paraparesis with power of $4+/ 5$ in the right lower limb and $4 / 5$ in the left lower limb. No sensory deficit was present. Deep tendon reflexes were exaggerated in both lower limbs. The rest of the neurological examination was normal. MRI of lumbosacral spine was done, which revealed two distinct lesions at L3 and L4 levels, of which the superiorly placed lesion was slightly hyperintense on $\mathrm{T} 1$ and hypointense on $\mathrm{T} 2$ sequences. Inferiorly placed lesion was hyperintense on $\mathrm{T} 1$ and hyperintense with an area of hypointensity on T2 sequences ( - Fig. $\mathbf{1}$ ). The cord was seen extending to the lower L2 level. She was then taken up for surgery where L3, L4 and L5 laminectomy was done, followed by midline posterior durotomy. There were two lesions, cranial gray-white firm cystic mass and caudal was yellow, fibrofatty lesion. Excision of the lesions and Commons Attribution-NonDerivative-NonCommercial-License, permitting copying and reproduction so long as the original work is given appropriate credit. Contents may not be used for commercial purposes, or adapted, remixed, transformed or built upon. (https://creativecommons.org/licenses/by-nc-nd/4.0/).

Thieme Medical and Scientific Publishers Pvt. Ltd. A-12, 2nd Floor, Sector 2, Noida-201301 UP, India 

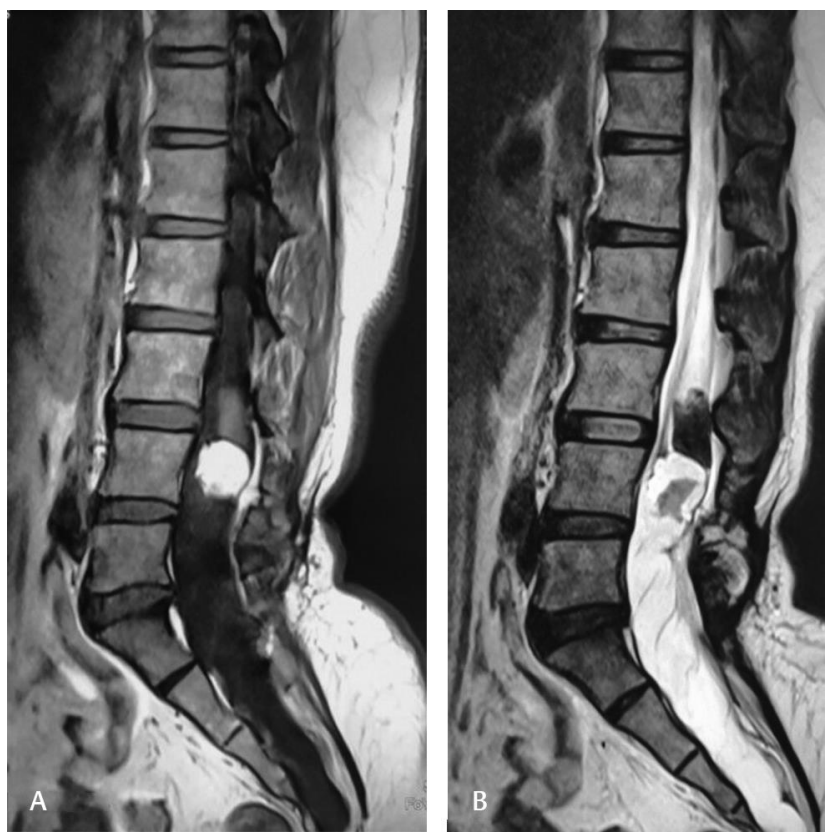

Fig. 1 (A) MRI T1-weighted image of midsagittal lumbosacral spine showing epidermoid cyst and lipoma tethering the cord. (B) MRI T2-weighted image of midsagittal lumbosacral spine showing epidermoid cyst and lipoma tethering the cord.

detethering of cord was done, followed by primary duroplasty. Histopathology was suggestive of cranial epidermoid cyst and caudal lipoma. Postoperatively, her paresthesia decreased in intensity and disappeared on 6 months of follow-up.

\section{Discussion}

Spinal region lipomas are usually associated with spinal dysraphisms, wherein the intraspinal component of the tumor communicates with the subcutaneous part of the tumor through a defect in the posterior elements of spine. It is thought that lipomas develop when there is premature disconnection of the cutaneous ectoderm from the forming neural tube. ${ }^{5}$ Dysraphic lipomas are generally associated with cutaneous anomalies like subcutaneous fatty masses, dermal sinus, dimple or hypertrichosis. ${ }^{6}$ Moreover, lipomas occurring predominantly in the lumbosacral region have more likelihood to be associated with congenital factors. Clinical presentation is usually with symptoms secondary to mass effect, owing to the size of the lesion. These tumors present with symptoms of progressive myelopathy, including gait difficulties, motor weakness, sensory symptoms, and sphincter incontinence.

Epidermoid cysts are rare of the central nervous system (CNS) tumors, benign in nature, with cranial being more common than spinal lesions; intraspinal ones account for less than $1 \%$ of all intraspinal lesions. ${ }^{3}$ Epidermoid cysts are mostly located in the thoracic region, while their presence in lumbar region is found to be very rare. ${ }^{7}$ The symptoms of the cyst are usually not specific and are secondary to mass effect on the cord, due to the progressively increasing size of the lesion. ${ }^{8.9}$ Patients are usually symptomatic for a longer duration, an average time of around 6 years, due to their slow growing nature. ${ }^{8,9}$
Concomitant existence of an epidermoid cyst adjacent to lipoma can be due to a form of disjunction, which leads to sequestration of multipotent cells in between the tissue layers that separate the skin from the deeper neuroectodermal structures. ${ }^{10}$

With the recent advances in imaging techniques, it has become increasingly easier to correctly diagnose a patient with such presentation. In spite of theoretical possibility of coexistence of the two lesions, there has been only one case report citing such incidence, that too in a young patient, stressing on the rarity of such cases. ${ }^{4}$

\section{Conclusion}

The coexistence of intradural lipoma and epidermoid cyst, in spite of theoretical possibility, is not commonly found. Such lesions should be considered in diagnosis when dealing with a patient with lumbar region pain and paresthesia in lower limbs, irrespective of the age. With the new advanced imaging techniques, accurate diagnosis of such lesions is now possible. The management in such cases should be planned accordingly for complete cure of the patient with least chances of recurrence.

\section{Conflict of Interest}

None declared.

\section{References}

1 Boop FA, Russell A, Chadduck WM. Diagnosis and management of the tethered cord syndrome. J Ark Med Soc 1992;89(7):328-331

2 Koyanagi I, Hida K, Iwasaki Y, et al. Radiological findings and clinical course of conus lipoma: implications for surgical treatment. Neurosurgery 2008;63(3):546-551

3 Amato VG, Assietti R, Arienta C. Intramedullary epidermoid cyst: preoperative diagnosis and surgical management after MRI introduction. Case report and updating of the literature. J Neurosurg Sci 2002;46(3-4):122-126

4 Koca I, Madenci E, Altindag O, et al. Epidermoid cyst and lipoma with tethered spinal cord: A case report. Dicle Med Journal 2012;39(1):136-138

5 Naidich TP, Blaser SI, Delman BN, et al. Congenital anomalies of the spine and spinal cord: embryology and malformations. In: Atlas SW, ed. Magnetic Resonance Imaging of the Brain and Spine. Philadelphia, PA: Lippincott Williams and Wilkins; 2002:1527-1537

6 Tavafoghi V, Ghandchi A, Hambrick GW Jr, Udverhelyi GB. Cutaneous signs of spinal dysraphism. Report of a patient with a tail-like lipoma and review of 200 cases in the literature. Arch Dermatol 1978;114(4):573-577

7 Lai SW, Chan WP, Chen CY, Chien JC, Chu JS, Chiu WT. MRI of epidermoid cyst of the conus medullaris. Spinal Cord 2005;43(5):320-323

8 Roux A, Mercier C, Larbrisseau A. Dube LJ, Dupuis C, Del Carpio R. Intramedullary epidermoid cysts of the spinal cord. Case report. J Neurosurg 1992;76(3):528-533

9 Lunardi P, Missori P, Gagliardi FM, Fortuna A. Long-term results of the surgical treatment of spinal dermoid and epidermoid tumors. Neurosurgery 1989;25(6):860-864

10 McLone D, Naidich TP, Spinal dysraphism: experimental and clinical. In: Holtzman RNN, Stein B, eds. The Tethered Spinal Cord. New York: Thieme-Stratton; 1985:14-28 